\title{
A Theory Generalized to Cage Effects in Radical Formation for Determining Initiator Efficiency
}

\author{
Katsukiyo ITO \\ Government Industrial Research Institute, Nagoya, \\ Kita-ku, Nagoya 462, Japan
}

(Received February 9, 1984)

\begin{abstract}
The probability $p_{\mathrm{B}}$ of a recombination between a radical produced at time zero and another produced subsequently by $\beta$-scission is formulated by solving diffusion equations. When the rate constant $k$ of $\beta$-scission is so high that $k \gg 10^{10} \mathrm{~s}^{-1}$, the same type as the Noyes equation is obtained from the equation for $p_{\mathrm{B}}$. When the rate of recombination is much higher than the relative diffusion rate of radicals, the same type as the Koenig equation is also obtained from $p_{\mathrm{B}}$. An equation, derived previously for the probability of recombination between radicals produced at time zero, is reestablished to explain the observed decomposition rate. On the basis of the above results, an initiator efficiency for radical polymerization is formulated.
\end{abstract}

KEY WORDS Azo- and Peroxy-Initiators / Solvent Cages / Diffusion

Equations / Stokes Equation / Viscosity / Recombination / Deomposition / Initiator Efficiency /

In radical polymerizations, azo and peroxy compounds are used as initiators. When such initiators decompose, geminate radicals are produced in a solvent cage. Initiator efficiency has been considered as a probability that the radicals escape from the solvent cage. ${ }^{1,2}$ The diffusion behavior of the geminate radicals has been investigated by many workers. ${ }^{3-10}$ The probabilities of recombination of radicals produced on the decomposition of a large number of initiators have been found to increase with increasing viscosity of the medium. However, there is a marked difference between the probability observed for the decomposition of $\mathrm{R}_{1} \mathrm{~N}=\mathrm{NR}_{2}\left(\mathrm{R}_{1}, \mathrm{R}_{2}=-\mathrm{CH}_{3} \text { or } \mathrm{CF}_{3}\right)^{3}$ and di-tert-butylperoxy oxalate ${ }^{4}$ and the probability observed for that of the other compounds. ${ }^{7}$ That is, the data in refs 3 and 4 could be correlated with $\eta$ on the basis of Noyes' theory, ${ }^{6}$ but the other data $^{7}$ could be correlated with $\eta^{1 / 2}$ on the Koenig's theory. In spite of such a difference, no other general theories correlating the Noyes and Koenig theories have been formulated.

The first aim on the present paper has been the determination of such a correlation. Further, an equation, previously derived for the probability of recombination between radicals produced at time zero, ${ }^{9,10}$ was reestablished to explain the relationship among the observed decomposition rate, $\beta$-scission, and viscosity on the basis of Stokes-Einstein equation. An initiator efficiency for free radical polymerization was formulated.

\section{THEORY}

In a previous paper ${ }^{10}$ on the decomposition of certain azo compounds, it was assumed that radicals and nitrogen are produced at the same time. In the present paper, the radical $\mathrm{RN}=\mathrm{N}$. produced from one-bond initiator defined in ref 5 is considered as $\mathrm{A}^{\prime}$. for more general treatment, and the reaction scheme is set up as

$$
\mathrm{I} \rightleftarrows \mathrm{A} \cdot+\mathrm{A}^{\prime} \cdot
$$


$\mathrm{A}^{\prime} \cdot \rightarrow \mathrm{B} \cdot+\mathrm{N}_{2}, \mathrm{CO}_{2}$, or the other $(\beta$-scission $)$

$\mathrm{A} \cdot+\mathrm{B} \cdot \rightarrow$ recombination products

When $\mathrm{A}^{\prime}$. diffuses from $\mathrm{A} \cdot$ by a distance $r$ during time $t$, the diffusion equation is given by

$$
\frac{\partial w_{\mathrm{A}}}{\partial t}=D_{\mathrm{A}}\left(\frac{\partial^{2} w_{\mathrm{A}}}{\partial r^{2}}+\frac{2}{r} \frac{\partial w_{\mathrm{A}}}{\partial r}\right)-k w_{\mathrm{A}}
$$

Equation 4 was solved under the appropriate initial and boundary conditions. ${ }^{9,10}$ Following Monchick, ${ }^{9}$ the probability of geminate recombination between $\mathrm{A} \cdot$ and $\mathrm{A}^{\prime}$. is given by

$$
\begin{aligned}
p_{\mathrm{A}} & \equiv 4 \pi a^{2} k_{0 \mathrm{~A}} \int_{0}^{\infty} w_{\mathrm{A}}(a, t) \mathrm{d} t \\
& =\frac{a k_{0 \mathrm{~A}}}{D_{\mathrm{A}}+a k_{0 \mathrm{~A}}+a\left(k D_{\mathrm{A}}\right)^{1 / 2}}
\end{aligned}
$$

where $a$ is nearly equal to the diameter of the A-cage. Another diffusion equation for particles $\mathrm{A} \cdot$ and $\mathrm{B} \cdot$ is given by

$$
\frac{\partial w_{\mathrm{B}}}{\partial t}=D_{\mathrm{B}}\left(\frac{\partial^{2} w_{\mathrm{B}}}{\partial r^{2}}+\frac{2}{r} \frac{\partial w_{\mathrm{B}}}{\partial r}\right)+k w_{\mathrm{A}}
$$

Following the previous reports, ${ }^{9,10}$ the initial and boundary conditions are,

$$
\begin{gathered}
w_{\mathrm{B}}=0 \quad \text { at } \quad t=0 \\
D_{\mathrm{B}}\left(\partial w_{\mathrm{B}} / \partial r\right)_{\mathrm{b}}=k_{0 \mathrm{~B}}\left(w_{\mathrm{B}}\right)_{\mathrm{b}} \\
w_{\mathrm{B}} \rightarrow 0 \quad \text { at } \quad r \rightarrow \infty
\end{gathered}
$$

The solution as $\bar{v} \equiv \int_{0}^{\infty} w_{\mathrm{B}}(r, t) \mathrm{d} t$ (see Appendix) is,

$$
\bar{v}=\frac{\left(k D_{\mathrm{A}}\right)^{1 / 2} \exp \left[\left(k / D_{\mathrm{A}}\right)^{1 / 2}(a-b)\right]}{4 \pi\left(D_{\mathrm{B}}+b k_{0 \mathrm{~B}}\right)\left[D_{\mathrm{B}}+a k_{0 \mathrm{~A}}+a\left(k D_{\mathrm{A}}\right)^{1 / 2}\right]}
$$

where $b$ is nearly equal to the diameter of the B-cage.

The probability of recombination in the Bcage is defined as eq 11 and calculated to be eq 12.

$$
p_{\mathrm{B}} \equiv 4 \pi b^{2} k_{0 \mathrm{~B}} \int_{0}^{\infty} w_{\mathrm{B}}(b, t) \mathrm{d} t\left[=4 \pi b^{2} k_{0 \mathrm{~B}} \bar{u}(b)\right]
$$

$$
=\frac{b^{2} k_{\mathrm{OB}}\left(k D_{\mathrm{A}}\right)^{1 / 2} \exp \left[\left(k / D_{\mathrm{A}}\right)^{1 / 2}(a-b)\right]}{\left(D_{\mathrm{b}}+b k_{\mathrm{OB}}\right)\left[D_{\mathrm{A}}+a k_{0 \mathrm{~A}}+a\left(k D_{\mathrm{A}}\right)^{1 / 2}\right]}
$$

\section{DISCUSSION}

When $a$ is nearly equal to $b$, an approximation such as eq 13 should be available. Further, when the reverse reaction of eq 1 is negligible, inequality 14 can be used.

$$
\begin{gathered}
\exp \left[\left(k / D_{\mathrm{A}}\right)^{1 / 2}(a-b)\right] \simeq 1 \\
a k_{0 \mathrm{~A}} \ll D_{\mathrm{A}}+a\left(k D_{\mathrm{A}}\right)^{1 / 2}
\end{gathered}
$$

On approximating eq 13 and inequality 14 , eq 12 reduces to:

$$
\frac{1}{p_{\mathrm{B}}} \simeq \frac{a}{b}\left(1+\frac{D_{\mathrm{B}}}{b k_{0 \mathrm{~B}}}\right)\left(1+\frac{D_{\mathrm{A}}^{1 / 2}}{a k^{1 / 2}}\right)
$$

When inequality 16 can be used, eq 15 becomes eq 17.

$$
\begin{array}{r}
k \gg D_{\mathrm{A}} / a^{2} \\
\frac{1}{p_{\mathrm{B}}} \simeq \frac{a}{b}\left(1+\frac{D_{\mathrm{B}}}{b k_{0 \mathrm{~B}}}\right)
\end{array}
$$

Using eq 18 (Stokes-Einstein equation) and $19,{ }^{10}$ eq 17 is rewritten as eq 20.

$$
\begin{gathered}
D=\boldsymbol{k} T / 3 \pi r_{0} \eta \\
k_{0}=v(2 \boldsymbol{k} T / 9 \pi m)^{1 / 2} \\
\frac{1}{p_{\mathrm{B}}} \simeq \frac{a}{b}\left[1+\frac{(\boldsymbol{k m})^{1 / 2}}{2.50 \pi v b r_{0}} \cdot \frac{T^{1 / 2}}{\eta}\right]
\end{gathered}
$$

where $r_{0} \simeq b$. This equation is similar to the Noyes equation ${ }^{3}$ except that his " $a$ " and " $b$ " are defined as the initial separation distance and the diameter of radicals, respectively; the value of 2.50 becomes $^{10} 3.84$ (in ref $9, k_{0}$ $(\equiv h)=v(k T / \pi m)^{1 / 2} / 4$. Thus, the value of 2.50 may become 4.71 ). To derive eq 20 , it should be noted that $k \gg 10^{10} \mathrm{~s}^{-1}$ is required by inequality 16 when $D_{\mathrm{A}} \simeq 10^{-5} \mathrm{~cm}^{2} \mathrm{a}^{-1}$ and $a \simeq$ $3 \times 10^{-8} \mathrm{~cm}$.

When inequality 21 can be used, eq 15 reduces to eq 22 .

$$
b k_{0 \mathrm{~B}} \gg D_{\mathrm{B}}
$$




$$
\frac{1}{p_{\mathrm{B}}} \simeq \frac{a}{b}\left(1+\frac{D_{\mathrm{A}}^{1 / 2}}{a k^{1 / 2}}\right)
$$

Using eq 18 , eq 22 is rewritten as

$$
\frac{1}{p_{\mathrm{B}}} \simeq \frac{a}{b}\left[1+\left(\frac{k}{3 \pi a^{2} r_{0} k}\right)^{1 / 2}\left(\frac{T}{\eta}\right)^{1 / 2}\right]
$$

This has the same form as the Koenig equation. $^{7}$ Koenig applied his equation to some data on the decomposition of $\mathrm{CH}_{3} \mathrm{~N}=\mathrm{NCH}_{3}$ when $p_{\mathrm{B}}>0.62$, as shown in ref 7 . However, application of the Koenig equation to Szwarc et al.'s data over a wider range of $p_{\mathrm{B}} \geq 0.11$ could not be carried out to a significant extent. Further, as shown in ref 3 , the Noyes equation is applicable to nearly all data on the decomposition of $\mathrm{CF}_{3} \mathrm{~N}=\mathrm{NCF}_{3}, \mathrm{CF}_{3} \mathrm{~N}=\mathrm{NCH}_{3}$, and $\mathrm{CH}_{3} \mathrm{~N}=\mathrm{NCH}_{3}$. Thus, the application of the Koenig equation and eq 23 to the data in ref 3 may not be possible. It is concluded that the application of the Noyes equation by Szwarc et al. can still be carried out to a significant extent.

The applicability of eq 5 should be examined in the light of the following analysis of the decomposition rate of the initiator. The observed decomposition rate constant is given as

$$
k_{\text {obsd }}=2 k_{\mathrm{d}}\left(1-p_{\mathrm{A}}\right)
$$

The introduction of eq 5 into eq 24 yields

$$
\frac{2 k_{\mathrm{d}}}{k_{\mathrm{obsd}}}=1+\frac{a k_{0 \mathrm{~A}}}{D_{\mathrm{A}}+a\left(k D_{\mathrm{A}}\right)^{1 / 2}}
$$

When $k \gg D_{\mathrm{A}} / a^{2}$, eq 25 is rewritten as

$$
\begin{aligned}
\frac{2 k_{\mathrm{d}}}{k_{\mathrm{obsd}}} & \simeq 1+\frac{k_{0 \mathrm{~A}}}{\left(k D_{\mathrm{A}}\right)^{1 / 2}} \\
& =1+\left[v\left(\frac{2 r_{0}}{3 m k}\right)^{1 / 2}\right] \eta^{1 / 2}
\end{aligned}
$$

Equation 27 has the same form as the Pryor and Smith equation, ${ }^{5}$

$$
\frac{k_{1}}{k_{\text {obsd }}}=1+\left(k_{-1} / A_{\mathrm{D}}\right)\left(\eta / A_{\mathrm{v}}\right)^{1 / 2}
$$

(using their terminology)
Table I. The calculated values of $\left(k_{-1} / A_{\mathrm{D}}\right)$ and $\left[v\left(2 r_{0} / 3 m k\right)^{1 / 2}\right]$ from the data ${ }^{8}$ on the decomposition of TMT

\begin{tabular}{cccccc}
\hline$\frac{\text { Temp }}{{ }^{\circ} \mathrm{C}}$ & 110 & 115 & 120 & 125 & 130 \\
\hline $10^{8} k_{-1} / A_{\mathrm{D}}$ & 19 & 13 & 9 & 6 & 4 \\
\hline$\frac{\left(\frac{2 r_{0}}{3 m k}\right)^{1 / 2}}{\text { poise }^{-1 / 2}}$ & 12 & 10 & 8 & 6 & 7 \\
\hline
\end{tabular}

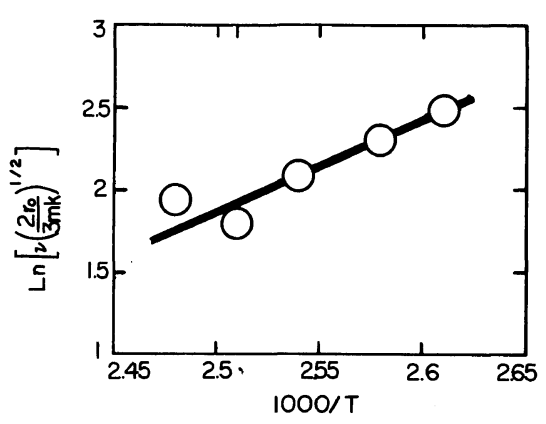

Figure 1. An analysis of the slope of eq 27 by the Arrhenius equation in the decomposition of TMT. ${ }^{8}$

Many data were analyzed using this equation. ${ }^{5,8}$ However, in nearly all cases, a larger value of $k_{-1}$ was calculated at lower temperature. This is typically shown in Table I for the decomposition of 1,1,4,4-tetramethyl-2tetrazene (TMT), ${ }^{8}$ where $A_{\mathrm{D}}$ is independent of temperature. Apparently, the $k_{-1}$-values are not consistent with the data for the usual rate constants. This means that the above Pryor and Smith equation is not applicable to the data on the decomposition of TMT. Thus, the same data were analyzed by eq 27 and the values obtained for $\left[v\left(2 r_{0} / 3 m k\right)^{1 / 2}\right]$ are shown in Table I. This value decreases with increasing temperature. Such temperature dependency is consistent with ordinary reaction kinetics, since the slope is proportional to $k^{-1 / 2}$. An analysis by the Arrhenius equation is shown in Figure 1. The activation energy was found to be $10 \pm 5 \mathrm{kcal} \mathrm{mol}^{-1}$. Further, $k \simeq 10^{13} v^{2}$ is 
K. Iто

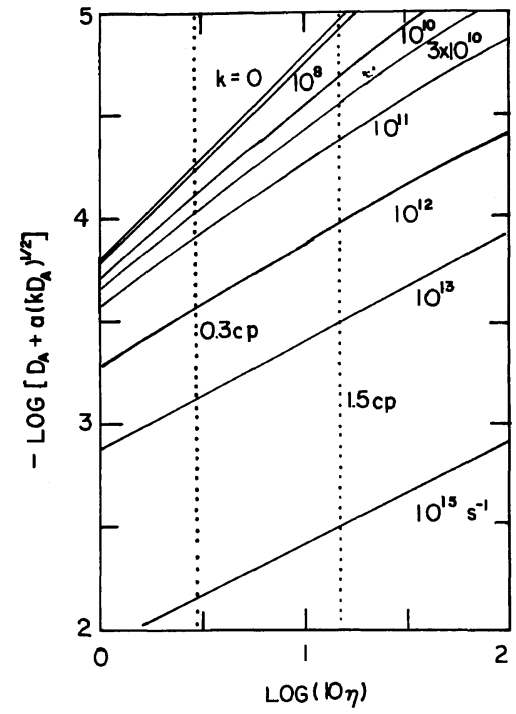

Figure 2. Dependency of $k_{\text {obsd }}$ on $\eta$ where $D_{\mathrm{A}}$ is calculated using the Stokes-Einstein equation as $D_{\mathrm{A}}=$ $1.62 \times 10^{-5} / \eta \mathrm{cP}\left(r_{0} \simeq a \simeq 3 \times 10^{-8} \mathrm{~cm}\right)$.

obtained when $r_{0} \simeq 3 \times 10^{-8} \mathrm{~cm}$ and $m \simeq 3 \times$ $10^{-23} \mathrm{~g}$. Thus, if $v \geq 0.1, k \geq D_{\mathrm{A}} / a^{2}\left(\simeq 10^{10} \mathrm{~s}^{-1}\right)$ may be satisfied. A further increase in $k$ $\left(\geq 10^{13} \mathrm{~s}^{-1}\right)$ eliminates the viscosity effect $\left(k_{\text {obsd }} \rightarrow 2 k_{\mathrm{d}}\right)$ of $\eta=0.3 \sim 1.5 \mathrm{cP}$ when carrying out ordinary experiments. ${ }^{3-8}$ This corresponds to $k_{\text {obsd }} \rightarrow k_{1}\left(1+k_{-1} / k_{\beta}\right) \rightarrow k_{1}$ when $k_{\beta} \gg k_{-1}$ in the Pryor and Smith equation. ${ }^{5}$ When $k_{\beta} \ll D_{\mathrm{A}} / a^{2}$, the other limit is written as

$$
\begin{aligned}
\frac{2 k_{\mathrm{d}}}{k_{\mathrm{obsd}}} & \simeq 1+\frac{a k_{0 \mathrm{~A}}}{D_{\mathrm{A}}} \\
& =1+\left[\operatorname{var}_{0}\left(\frac{2 \pi}{m k}\right)^{1 / 2}\right]\left(\frac{\eta}{T^{1 / 2}}\right)
\end{aligned}
$$

In this case, the decomposition rate can be correlated with $\eta$. The change in viscosity dependency between $\alpha=1 / 2$ (eq 27) and $\alpha=1$ (eq 29) is shown in Figure 2. The change in $\alpha$ is pronounced when $10^{12}>k>10^{8}$. Pryor and Smith stated that an expected dependency is in the range of $\alpha=0.70 \sim 0.75$ and a rate constant for the $\beta$-scission for the decomposition of hypothetical initiator is $k_{\beta}=3 \times 10^{10} \mathrm{~s}^{-1}$. From eq 25 and the Stokes-Einstein equation as eq 18 , such a $k_{\beta}$-value may correspond to

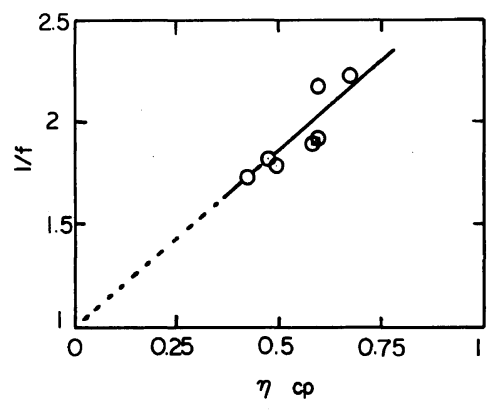

Figure 3. Relationship between $f$ and $\eta$ in the polymerization of styrene initiated by AIBN at $60^{\circ} \mathrm{C} .{ }^{11}$

$k \simeq 10^{11} \mathrm{~s}^{-1}$, since $\alpha \simeq 0.72$ in the range of $\eta=0.3 \sim 1.5 \mathrm{cP}$.

In radical polymerization, primary radicals which escape from the solvent cages react with monomer, solvent, polymer radical, etc. However, such reactions should not affect the cage reactions since their rates are negligibly slow compared to those of the cage reactions. This comparison is presented in detail in ref 10 . Consider the usual polymerization system of which the addition of the primary radical to monomer predominates. ${ }^{1,2}$ In this system, nearly all the primary radicals can initiate the propagation. Thus, initiator efficiency is defined as,

$$
f \equiv \frac{D_{\mathrm{A}}+a\left(k D_{\mathrm{A}}\right)^{1 / 2}\left(1-p_{\mathrm{B}}\right)}{D_{\mathrm{A}}+a k_{0 \mathrm{~A}}+a\left(k D_{\mathrm{A}}\right)^{1 / 2}}
$$

When $k \gg 10^{10} \mathrm{~s}^{-1}$ and $a \simeq b$, it is reduced to,

$$
\begin{aligned}
f & \simeq 1-p_{\mathrm{B}} \\
& \simeq \frac{D_{\mathrm{B}}}{D_{\mathrm{B}}+b k_{0 \mathrm{~B}}}
\end{aligned}
$$

Equation 30 is a better definition than the initiator efficiency previously derived ${ }^{10}$ and the previous efficiency is equal to eq 32 . Using $A$ $\left[\equiv(m \boldsymbol{k} / 24)^{1 / 2} / \pi b^{2}\right] \simeq 10^{-5} \quad\left(b \simeq r_{0}\right),{ }^{3} \quad$ eq 32 is rewritten as,

$$
\frac{1}{f}=1+10^{5} v \eta / T^{1 / 2}
$$

This equation is applicable to the data on 
initiator efficiencies in the polymerization of styrene initiated by $2,2^{\prime}$-azobisisobutyronitrile (AIBN) at $60^{\circ} \mathrm{C}$ (Figure 3). ${ }^{11}$ The $v$-value was found to be 0.05 which is in good agreement with $v=0.1 \sim 0.03$ obtained by Szwarc et al. ${ }^{3}$

\section{APPENDIX}

With the substitutions $w_{\mathrm{A}} \equiv u(r, t) \exp (-k t)$ and $w_{\mathrm{B}} \equiv v(r, t) \exp (-k t)$, eq 4 and 6 are rewritten as

$$
\begin{aligned}
& \frac{\partial u}{\partial t}=D_{\mathrm{A}}\left(\frac{\partial^{2} u}{\partial r^{2}}+\frac{2}{r} \frac{\partial u}{\partial r}\right) \\
& \frac{\partial v}{\partial t}=D_{\mathrm{B}}\left(\frac{\partial^{2} v}{\partial r^{2}}+\frac{2 \partial v}{r \partial r}\right)+k(u+v)
\end{aligned}
$$

In view of the Laplace transformation, eq A3 and $\mathrm{A} 4$ are set up as

$$
\begin{aligned}
& \bar{u} \equiv \int_{0}^{\infty} u(r, t) \exp (-k t) \mathrm{d} t\left(\equiv \int_{0}^{\infty} w_{\mathrm{A}} \mathrm{d} t\right) \\
& \bar{v} \equiv \int_{0}^{\infty} v(r, t) \exp (-k t) \mathrm{d} t\left(\equiv \int_{0}^{\infty} w_{\mathrm{B}} \mathrm{d} t\right)
\end{aligned}
$$

The solution for $\bar{u}$ is, ${ }^{9}$

$$
\bar{u} \equiv \frac{\exp \left[\left(k / D_{\mathrm{A}}\right)^{1 / 2}(a-r)\right]}{4 \pi\left[a k_{0 \mathrm{~A}}+D_{\mathrm{A}}+a\left(k D_{\mathrm{A}}\right)^{1 / 2}\right] r}
$$

Equation A2 becomes,

$$
\frac{d^{2}(r \bar{v})}{\mathrm{d} r}+\frac{k}{D_{\mathrm{B}}} \cdot r \bar{u}=0
$$

The boundary conditions become,

$$
\begin{aligned}
& D_{\mathrm{B}}(\mathrm{d} \bar{v} / \mathrm{d} r)_{\mathrm{b}}=k_{0 \mathrm{~B}} \bar{v}(\mathrm{~b}) \\
& \bar{v} \rightarrow 0 \quad \text { at } \quad r \rightarrow \infty
\end{aligned}
$$

Introducing eq A5 into eq A6 and solving A6 under the conditions of eq $A 7$ and $A 8$, eq 10 is obtained.

\section{NOMENCLATURE}

$$
\begin{array}{ll}
\eta & =\text { solvent viscosity } \\
\mathrm{I} & =\text { initiator } \\
\mathrm{A} \cdot, \mathrm{A}^{\prime} \cdot, \mathrm{B} \cdot & =\text { radicals }
\end{array}
$$

$=$ relative distance between radicals

$=$ time

= probability per unit volume for finding $\mathrm{A}$. and $\mathrm{A}^{\prime}$.

$=$ probability per unit volume for finding $\mathrm{A} \cdot$ and B.

$=$ relative diffusion constant for $\mathrm{A} \cdot$ and $\mathrm{A}^{\prime}$.

$=$ relative diffusion constant for $\mathrm{A} \cdot$ and $\mathbf{B}$.

$=$ rate constant of reaction of eq 2

$=$ reaction radius between $A^{*}$ and $A^{\prime}$.

$=$ reaction radius between $A \cdot$ and $B$.

= probability of recombination between $\mathrm{A}$. and $\mathrm{A}^{\prime} \cdot$ in the A-cage

$=$ probability of recombination between $\mathrm{A}$. and $\mathrm{B}$ - in the B-cage

$=$ initiator efficiency for free radical polymerization

$=$ specific rate between $\mathrm{A} \cdot$ and $\mathrm{A}^{\prime} \cdot$ in the $\mathrm{A}$ cage

$=$ specific rate between $\mathrm{A}$ - and $\mathrm{B}$ - in the $\mathrm{B}$ cage

$=$ Boltzmann constant

$=$ absolute temperature

$=$ reaction probability per collision between radicals

$=$ molecular weight of radicals calculated as ${ }^{9}$ $1 / m=1 / m_{1}+1 / m_{2}$

$=$ observed decomposition rate constant

$=$ power of $\eta$ on $k_{\text {obsd }}$

$=$ diameter of radical

Acknowledgment. The author wishes to thank Research Manager T. Komai and his staffs, Nippon Oil \& Fats Co., for their interest in and valuable comments on this work.

\section{REFERENCES}

1. P. J. Flory, "Principles of Polymer Chemistry," Cornell University Press, Ithaca, New York, 1953.

2. Kh. S. Bagdasa'yan, "Theory of Free-Radical Polymerization," Asakura Shoten for Japanese translation, Tokyo 1964; Israel Scientific translation, Jerusalem, 1968.

3. O. Dobis, J. M. Pearson, and M. Szwarc, J. Am. Chem. Soc., 90, 278 (1968); K. Chakravorty, J. M. Pearson, and S. Szwarc, ibid., 90, 283 (1968).

4. E. Niki and Y. Kamiya, J. Am. Chem. Soc., 96, 2129 (1974).

5. W. A. Pryor and K. Smith, J. Am. Chem. Soc., 92, 5403 (1970); W. A. Pryor, E. H. Morkved, and H. Bickley, J. Org. Chem., 37, 1999 (1972).

6. R. M. Noyes, Progr. Reaction Kinetics, 1, 131 (1961).

7. T. Koenig and M. Deinzer, J. Am. Chem. Soc., 90, 7014 (1968); T. Koenig, ibid., 91, 2558 (1969). 


\section{K. Iто}

8. T. Oda, T. Maeshima, and K. Sugiyama, J. 10. K. Ito, J. Polym. Sci., A-1, 10, 57 (1972).

Macromol. Sci.-Chem., A13, 715 (1979).

11. T. Yamamoto and T. Yamamoto, Nippon Kagaku

9. L. Monchik, J. Chem. Phys., 24, 381 (1956). Kaishi, 1300 (1972). 